\title{
Assessing Fracture Resistance of non Vital Teeth Using Two Different Composite Systems: Short-Fibre-Reinforced Composite and Glass Fibre Post with Microfilled Hybrid Composite
}

\author{
SANDA ILEANA CIMPEAN ${ }^{1}$, IOANA-SOFIA POP-CIUTRILA ${ }^{1}$, SMARANDA BUDURU ${ }^{2 *}$, \\ LILIANA LACRAMIOARA PAVEL ${ }^{3 *}$, DANIELA FLORENTINA FLOREA ${ }^{4}$, \\ ADA GABRIELA DELEAN ${ }^{1}$, MARIOARA MOLDOVAN ${ }^{5}$, MIRCEA CRISTIAN DUDESCU ${ }^{6}$, \\ SORIN BERBECE ${ }^{3}$, DOINA CARINA VOINESCU ${ }^{3}$, ADRIAN BEZNEA ${ }^{3}$, \\ MARIUS NEGUCIOIU ${ }^{2}$, VICTORITA STEFANESCU ${ }^{3}$ \\ ${ }^{1}$ University of Medicine and Pharmacy "Iuliu Hatieganu", Department of Conservative Dentistry and Endodontics, 33 \\ Motilor Str., 400001, Cluj-Napoca, Romania \\ ${ }^{2}$ University of Medicine and Pharmacy "Iuliu Hatieganu", Department of Prosthetics and Dental Materials, 32 Clinicilor Str., \\ 400001 Cluj-Napoca, Romania \\ ${ }^{3}$ Dunarea de Jos University of Galati, Faculty of Medicine and Pharmacy, 47 Domneasca Str., 800008, Galati, Romania \\ ${ }^{4}$ University of Medicine and Pharmacy "Iuliu Hatieganu", Department of Conservative Dentistry and Endodontics, 33 \\ Motilor Str., 400001, Cluj-Napoca, Romania \\ ${ }^{5}$ Babes-Bolyai University, "Raluca Ripan" Chemistry Institute, Department of Polymeric Composites, 1-3 Fantanele Str., \\ 400327, Cluj-Napoca, Romania \\ ${ }^{6}$ Technical University in Cluj-Napoca, Department of Mechanical Engineering, 103-105 Muncii Blvd., 400641, Cluj-Napoca, \\ Romania
}

\begin{abstract}
Posterior endodontically treated teeth are exposed to risk fracture due to the great masticatory forces developed in the area. Fiberglass posts are considered a practical solution for such situations, but their main disadvantage yet remains the poor adhesion to the remaining tooth structures. The purpose of the present study was to evaluate a material that could replace the use of fiberglass posts on posterior teeth. 32 premolars were selected and divided into 4 groups $(n=8)$ : the first group was considered the control group; the second group was composed of endodontically treated teeth that were filled with gutta-percha, but without any coronal restoration; the third group was composed of teeth that received the same endodontic treatment as in the second group but were restored with a fibreglass post and a light cured microfilled hybrid composite material; the fourth group was similar to the third one, except teeth were restored with a short-fibre-reinforced composite (EverX Posterior, GC Europe $N . V .$, Leuven, Belgium) and a microfilled hybrid composite over it. The fracture resistance of all the teeth was tested using a universal testing device. One-way ANOVA and the Tukey post-hoc variation tests for multiple comparisons were used to analyze the results. The short-fibre-reinforced composite material increased the fracture resistance of endodontically treated teeth (1159.42 N), twice as much as that obtained by using fiberglass posts $(522.35 \mathrm{~N}))$. Within the limitations of the present study, EverX Posterior represents a better alternative compared to fiberglass posts in the crown and root reconstruction of posterior endodontically treated teeth.
\end{abstract}

Keywords: EverX Posterior, post, fiberglass, endodontic treatment, dental fracture

\section{Introduction}

Ensuring fracture resistance of endodontically treated teeth in the lateral area, on which the masticatory forces predominantly act, is one of the major challenges of research in the dental field. These teeth are generally more susceptible to fracture compared to vital teeth. This major disadvantage is particularly due to the lack of root and crown vascularization, as well as the loss of a large amount of healthy dental tissue as a consequence of carious lesions or crown fracture, to which the preparation 
of the access cavity and of the lodge for application of the fiberglass posts or post-and-core restorations is added [1-12].

Endodontically treated teeth with fiberglass posts and composite material are much more resistant to fracture compared to those without fiberglass posts [12]. Increased resistance to fracture of teeth occurs due to the fact that the fiberglass posts, with a modulus of elasticity similar to that of the tooth, have the role of distributing masticatory forces along the root and then in the periodontal tissues [13-18]. These fiberglass posts have the property of resisting corrosion, while also having a high tensile strength [19, 20]. However, the major problem of fiberglass posts remains the adhesion to root dentin, the weakest link of this chain of reconstructive materials.

Recent studies have revealed a new restorative dental material, which represents a combination between composite resin and fiberglass. Fiberglass was introduced into the composite resin [21] in order to increase fracture resistance of the dental restoration and the restored tooth [22-26]. This material intended for root reconstruction, in the coronary third of the root, and even more coronary in the cervical and middle third of the dental crown, consists of a resin matrix, an E-glass fibre network and inorganic particulate fillers [27-29]. Some recent studies carried out on this type of materials show an increase in their fracture strength compared to composite materials [24, 25].

However, there are few studies in the literature that analyse the effects of this type of coronary reconstruction material on the resistance period of devitalised teeth. Thus, the purpose of the present study was to evaluate the fracture strength of a recent fiberglass reinforced resin material (EverX Posterior; GC Europe NV, Leuven, Belgium) compared to that of fiberglass posts applied to endodontically treated teeth. The null hypothesis used in this study was that fiberglass posts or fiberglass reinforced composite resins do not increase the fracture resistance of direct composite reconstructions performed on endodontically treated teeth.

\section{Materials and methods}

\subsection{Teeth preparation}

In this study, 32 premolars that were extracted for orthodontic purposes or due to periodontal reasons were selected. Inclusion criteria were: approximately similar crown size, lack of carious lesions or endodontic treatments, and lack of fracture lines. Teeth were disinfected with sodium hypochlorite 5.25\% (Cloraxid 5.25\%; Cerkamed, StalowaWola, Poland) for $48 \mathrm{~h}$, cleaned with brushes and polishers under continuous water flow, and then stored in physiological serum. Subsequently, the teeth were divided into 4 groups $(\mathrm{n}=8)$. A MOD (mesio-occlusal-distal) cavity was prepared on each of the premolars from groups 2, 3 and 4. Finally, the cavities had $3 \mathrm{~mm}$ in height and $3 \mathrm{~mm}$ in width. The distance from the cemento-enamel junction (=CEJ) to the edge of the gingival wall was $1.5 \mathrm{~mm}$. The thickness of the vestibular and oral walls was about $2.5 \mathrm{~mm}$.

The groups of teeth were as follows:

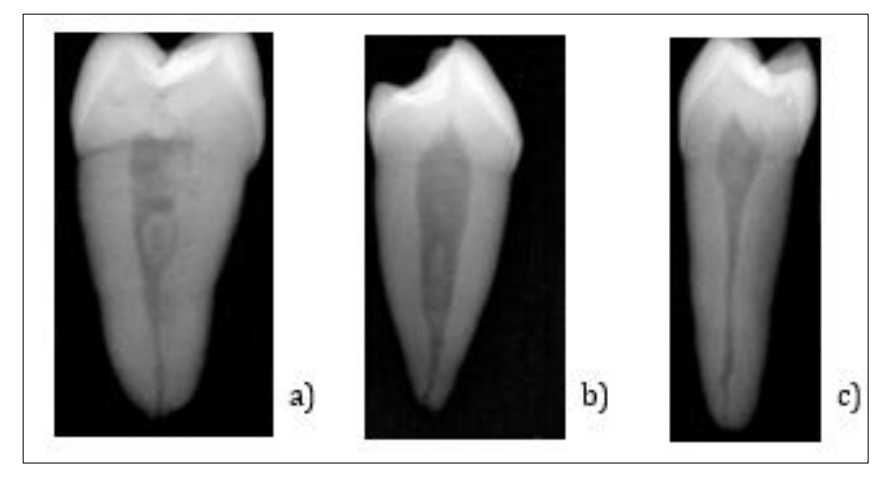

Figure 1 Preoperative radioographs of the premolars in group $1(\mathrm{a}, \mathrm{b}, \mathrm{c})$ 
Group 1 - sound premolars representing the control group (Figure 1).

Group 2 - premolars treated endodontically using a rotary system (2Shape; Micro-Mega, Besançon, France), and then endodontically filled using the combined thermomechanical condensation technique: cold lateral condensation of the apical third and thermal compaction filling of the coronal two thirds. A resin-based sealant (Adseal; Meta Biomed, Cheongju-si, Korea) and 2\%-taper guttapercha cones with a diameter corresponding to the prepared canal (Guttapercha Points; Meta Biomed, Cheongju-si, Korea) were used to seal the canal. After filling each tooth, a control radiograph of the endodontic treatment was performed. These teeth presented in the end a coronary MOD cavity which was not restored.

Group 3 - premolars treated and filled endodontically in the same manner as the teeth in group 2. At 24h after the endodontic treatment was completed, with the help of special burrs (Largo Peeso Reamer; Dentsply Sirona, Bensheim, Germany), 2/3 of the length of each canal was opened and a fiberglass post (Reforpost; Angelus, Londrina, Brazil) was applied according to the manufacturer's instructions. Before being applied into the canal, the post was cut at a certain level, in such a way that after insertion into the canal, its coronary extremity was situated at a distance of approximately $2 \mathrm{~mm}$ from the occlusal edge of the final restoration (Figure 2). Both the adhesive system (Futurabond DC Single Dose; VOCO, Cuxhaven, Germany), as well as the reconstruction cement applied around the post (Rebilda DC; VOCO, Cuxhaven, Germany) were of the dual-cure type, in order to allow a complete polymerisation of the two materials. The occlusal portion of the MOD cavity was then reconstructed with a light cured radiopaque microfilled hybrid composite designed for posterior teeth (G-aenial P-A2; GC Europe NV, Leuven, Belgium).The adhesive system used in this case was a single component total-etch dental adhesive (OptiBond Solo Plus; Kerr, Orange, CA, USA), applied according to the manufacturer's instructions (Figure 2).

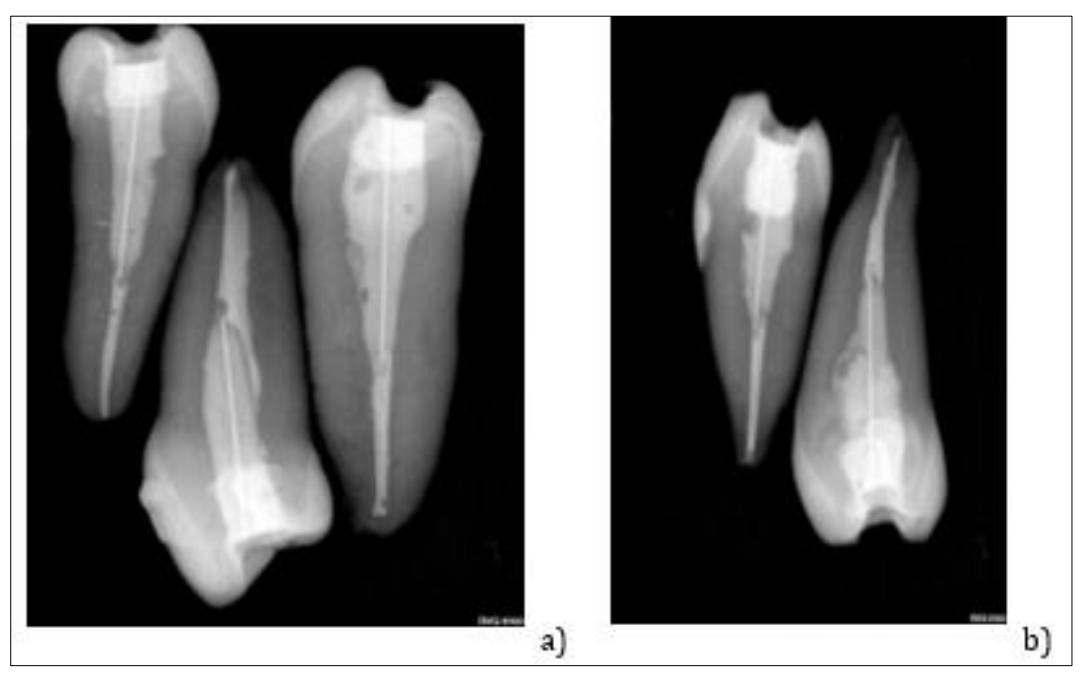

Figure 2 Postoperative radiographs of the premolars in group 3, after applying the fiberglass post $(a, b)$

Group 4 - premolars treated and filled endodontically in an identical manner as the teeth of group 2. A portion of approximately $2 \mathrm{~mm}$ of guttapercha was removed from the coronal part of the root canal, and then the coronal MOD cavity was washed and dried before applying the same adhesive system as the one used for the occlusal portion of the MOD cavity in group 3 (OptiBond Solo Plus). After light curing for $20 \mathrm{~s}$, the cavity was filled in successive $2 \mathrm{~mm}$ layers with fiberglass reinforced composite (EverX Posterior; GC Europe N.V., Leuven, Belgium) up to a distance of approximately $2 \mathrm{~mm}$ from its occlusal surface. The rest of the occlusal cavity was filled with the microfilled hybrid composite used previously in group 3 (G-aenial P-A2 (Figure 3). 
Figure 3. A premolar from group 4, after coronary reconstruction with EverX Posterior and microfilled hybrid composite

The materials used for the reconstruction of the endodontically treated teeth from groups 3 and 4 are listed in Table1 [30, 31]. All the teeth of the 4 groups were kept in physiological serum until the moment of incorporation in acrylic resin. The purpose of the incorporation was to reproduce the alveolar bone and the periodontal ligament system through dental materials. To mimic alveolar bone, a self-curing acrylic resin (Premacryl Plus; SpofaDental, Poland) was used, and a fluid impression material (Elite HD Light Body; Zhermack, BadiaPolesine, Italy) was used to mimic ligament laxity. A putty impression material (Elite HD Putty Soft; Zhermack, BadiaPolesine, Italy) was used to obtain the conformers. Before embedding the teeth in acrylate, they were insulated up to $2 \mathrm{~mm}$ from the CEJ with red wax. This was achieved by placing them perpendicularly into a melted wax bath (Figure 4).

Table 1. Materials used for teeth reconstruction

\begin{tabular}{|c|c|c|}
\hline Material & Type & Chemical composition \\
\hline G-aenial Posterior & MFR hybrid composite & $\begin{array}{l}\text { UDMA, dimethacrylate co-monomers (bis-GMA } \\
\text { free), } \\
\text { Fluoroaluminosilicate, fumed silica, pre-polymerized } \\
\text { fillers (silica, strontium and lanthanoid fluoride), } \\
\text { pigments, catalysts (CQ and amine) }\end{array}$ \\
\hline EverX Posterior & $\begin{array}{l}\text { Short- fibre-reinforced } \\
\text { composite }\end{array}$ & $\begin{array}{l}\text { Bis-GMA, PMMA, } \\
\text { E-glass fibres, barium borosilicate glassfiller }\end{array}$ \\
\hline Optibond Solo Plus & $\begin{array}{l}\text { Single component total-etch } \\
\text { dental adhesive }\end{array}$ & $\begin{array}{c}\text { Ethanol, 2-hydroxyethyl methacrylate, 2-hydroxy- } \\
\text { 1,3-propanediyl bismethacrylate, Alkali } \\
\text { fluorosilicates }(\mathrm{Na})\end{array}$ \\
\hline Futurabond DC & $\begin{array}{l}\text { Self-etch dual-cured } \\
\text { adhesive for all light-, dual- and } \\
\text { self-cured resin materials }\end{array}$ & $\begin{array}{l}\text { Organic acids, Bis-GMA, HEMA, TMPTMA, } \\
\text { BHT, ethanol, fluorides, CQ, amine, catalysts }\end{array}$ \\
\hline Rebilda DC & $\begin{array}{l}\text { Dual-curing flowable core } \\
\text { build-up and post luting system }\end{array}$ & $\begin{array}{c}\text { Bis-GMA, UDMA, DDDMA, BHT, } \\
\text { dibenzoylperoxide, CQ, silica, bariumborosilicate, } \\
\text { glass ceramic, accelerators }\end{array}$ \\
\hline
\end{tabular}




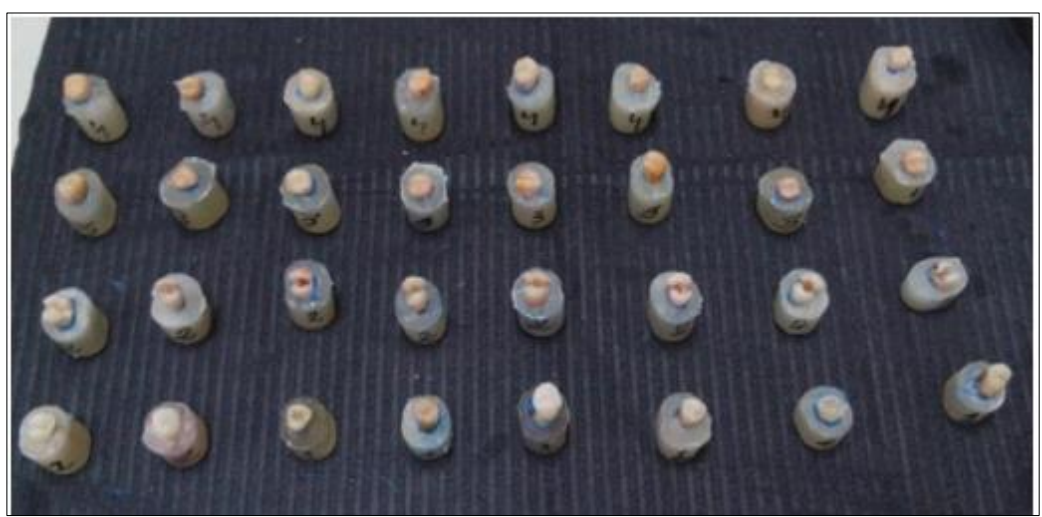

Abbreviations: MFR: microfilled resin, PMMA: polymethyl methacrylate, BHT: butylhydroxytoluene, BIS-EMA: ethoxylated bisphenol A glycol dimethacrylate, Bis-GMA: bisphenol A diglycidyl methacrylate, CQ: camphorquinone, DDDMA: dodecanediol dimethacrylate, HEMA: 2-hydroxyethyl methacrylate, PENTA: dipentaerythritol pentaacrylate monophophate, UDMA: urethane dimethacrylate, TCB: butan-1,2,3,4-tetracarboyxlic di-2-hydroxyethylmethacrylate ester, TEGDMA: triethylene glycol dimethacrylate, TMPTMA: trimethylolpropane trimethacrylate

Figure 4. The teeth inserted in acrylate resin and impression material

\subsection{Mechanical testing of the teeth}

To test the fracture resistance of the teeth treated in this study, a universal testing machine was used (Instron 6800; INSTRON, Norwood, MA, USA). The embedded teeth were inserted individually into a rectangular aluminium device, created according to the acrylate's dimensions, in order to minimize the possibility of movement of the specimen during the test and thus reducing the risk of erroneous measurements. The metallic device was fixed on the support of the test device, and its dimensions were those in Figure 5. The force was applied perpendicularly to the occlusal surface of the tooth using a sphere of $6 \mathrm{~mm}$ in diameter, at a constant velocity of $1 \mathrm{~mm} / \mathrm{min}$, until the tooth fractured (Figure 6). The force was measured by the device in Newtons $(\mathrm{N})$ and was represented on a scale. The scale corresponded to a group of teeth. The maximum values of the force were marked with geometric figures on the scale.

\subsection{Statistical analysis}

The results of the mechanical testing were analysed using the one-way ANOVA and the Tukey posthoc variation tests for multiple comparisons. To describe the variability of measured forces, central tendency descriptors (mean, median) along with the 95\% confidence intervals for means and standard deviations (SD) of these variables have been computed.

The level of statistical significance was set at $\alpha=0.05$. Data was collected using Microsoft $®$ Excel 2010 and the statistical analyses were performed using IBM SPSS 20 (IBM, Armonk, New York, USA).

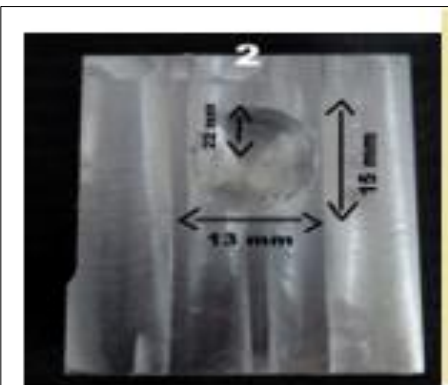

a

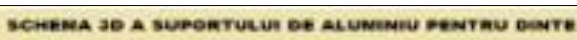

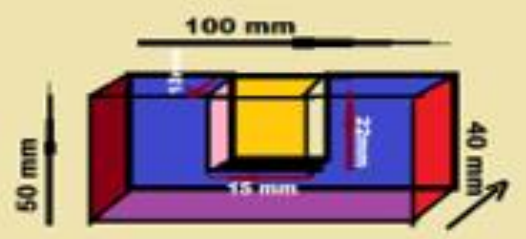

b

Figure 5. The metal device (a) together with its size diagram (b) 


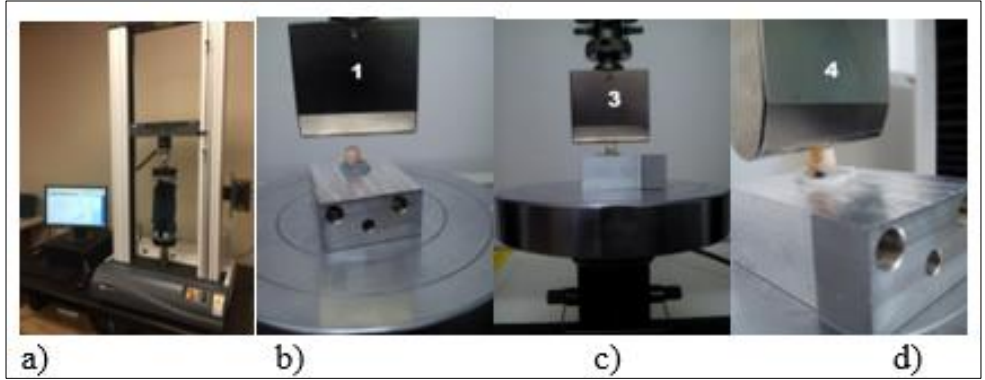

Figure 6. The Tester (a); Tooth clamping technique (b,c);

Compression (d)

\section{Results and discussions}

\subsection{Results}

The test results were saved as tables and graphs for each group (Figure 7).

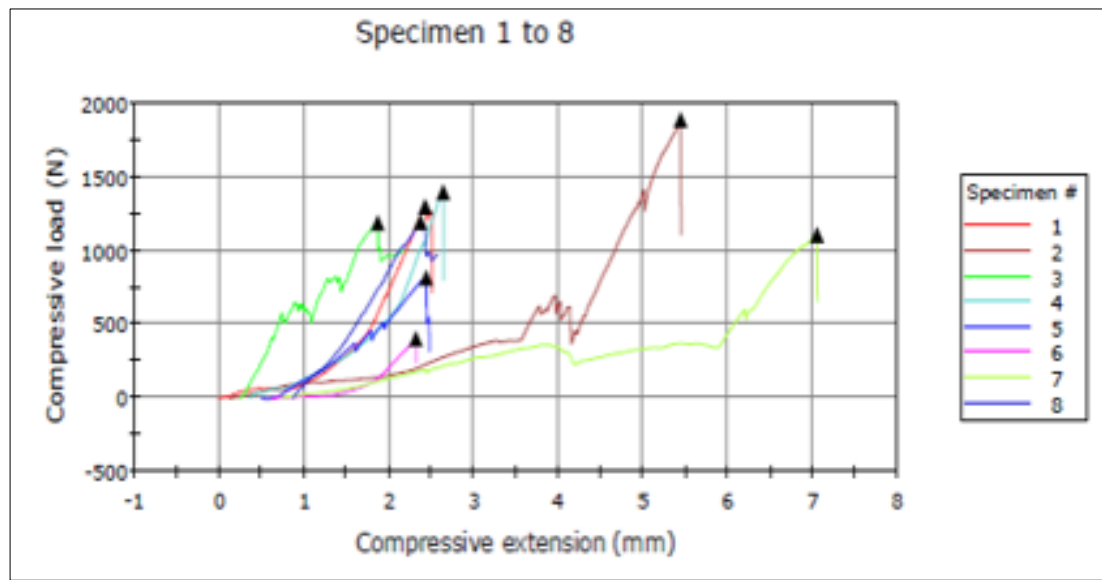

Figure 7. Graphic representation of maximum fracture strength for group 4

The average values of the fracture strength, expressed in Newtons $(\mathrm{N})$, corresponding to the four groups of teeth are displayed in Table 2 and are increasing as follows:

$$
\text { group } 2<\text { group } 1<\text { group } 3<\text { group } 4
$$

Table 2. The average values of the forces at which tooth fracture occurred, for each group of teeth

\begin{tabular}{|c|c|c|c|c|c|c|}
\hline Group & $\begin{array}{c}\text { Nr. Of } \\
\text { teeth }\end{array}$ & $\begin{array}{c}\text { Mean fracture } \\
\text { force (N) }\end{array}$ & $\begin{array}{c}\text { Standard } \\
\text { deviation }\end{array}$ & Median & Minimum & Maximum \\
\hline 1 & 8 & 655.38 & 452.26801 & 525.57 & 237.52 & 1537.66 \\
\hline 2 & 8 & 432.2 & 193.6561 & 339.38 & 230.58 & 709.18 \\
\hline 3 & 8 & 522.35 & 226.2907 & 564.12 & 155.73 & 748.89 \\
\hline 4 & 8 & 1159.42 & 428.8827 & 1189.21 & 403.41 & 1881.29 \\
\hline
\end{tabular}


As can be seen from the average values of fracture resistance, the group with the highest fracture resistance was group 4, in which the teeth were treated endodontically and reconstructed with fiberglassreinforced composite. The average strength of group 4 has been shown to be much greater than that of sound teeth. The difference between the average values of fracture resistance in the first three groups was not very pronounced. As expected, the group with the least fracture resistance was group 2, in which teeth were only treated endodontically, without being subsequently reconstructed in the coronal part. The comparison between the fracture resistance values of the 4 groups of teeth is represented in the graphics of Figures 8 and 9.

The one-way ANOVA test revealed highly significant differences $(p<0.001)$ between groups 1,2 and 3 when compared to group 4 . When compared two by two, the fracture resistance of the first three groups showed also significant differences $(\mathrm{p}<0.01)$.

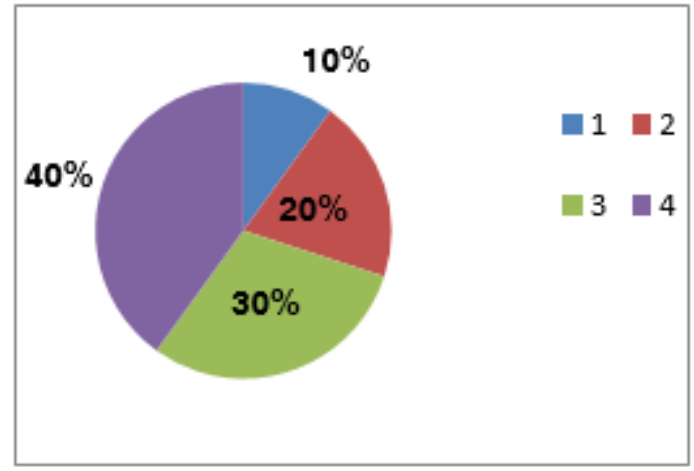

Figure 8. The fracture resistance of the teeth of the four groups, represented as a percentage

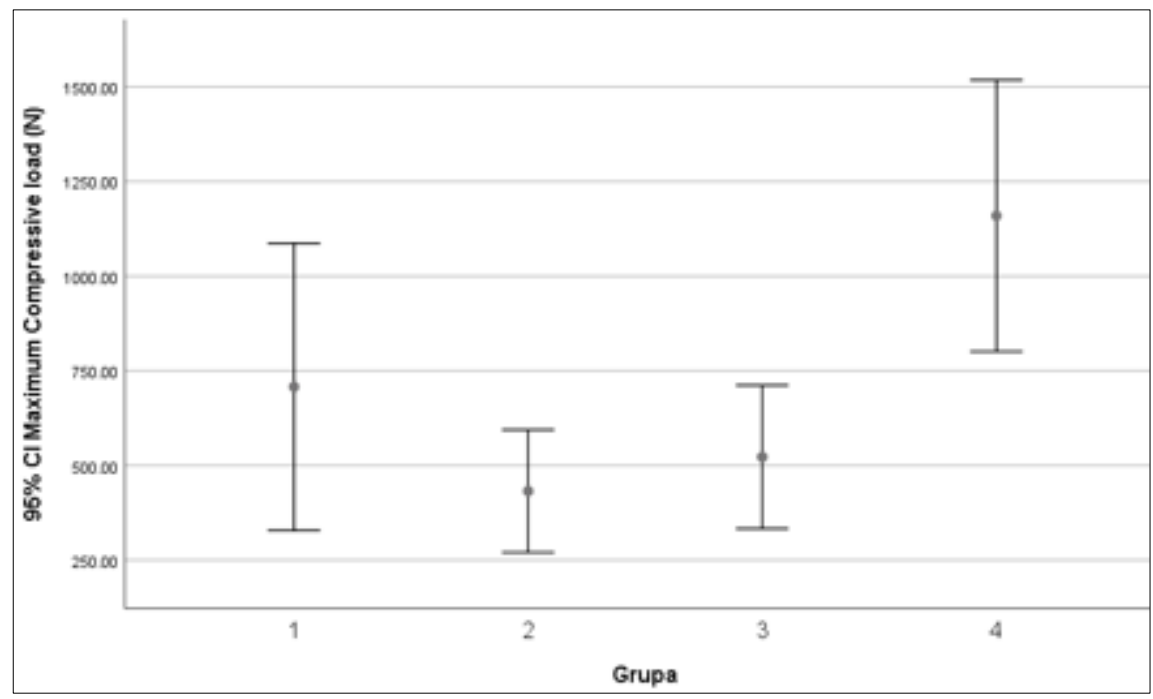

Figure 9. Degree of fracture resistance and $95 \%$ confidence interval of the teeth in the 4 groups

\subsection{Discussion}

The ideal reconstruction of a posterior endodontically treated tooth implies the improvement of its mechanical strength and the prevention of fracture propagation, but also the anatomical and functional restoration of the tooth. Studies have shown multiple causes due to which an endodontically treated tooth may fracture: large coronal destruction, lack of two or more coronal walls, patient's age, first endodontic treatment or endodontic retreatment, achievement of the intraradicular post housing or removal of large amounts of sound dentin, removal of an endodontic post [2-6]. 
The purpose of the present study was to evaluate the biomechanical behavior of a newly introduced fiberglass-reinforced composite (EverX Posterior) compared to the consecrated glass fiber post reconstruction ment to restore the coronal part of endodontically treated teeth. Carrying out a reconstruction that reduces the risk of fracture of the remaining dental structures is fundamental for the future of the tooth and the reconstruction. At the same time, MOD cavities have been prepared on the tested teeth due to the fact supported by the literature that this type of cavity produces the greatest decrease in the tooth's resistance to masticatory forces [32]. In order to evaluate the distribution of the masticatory and occlusal loads on the crowns of the premolars, the forces are usually applied in the central fossa and parallel or oblique to the tooth axis. Also, it is known that premolars are the most susceptible teeth to vertical fractures, due to the anatomical shape of their root.

The results of this in vitro study allowed us to partially reject the null hypothesis, because it was observed after testing that endodontically treated and coronally reconstructed teeth with fiberglass reinforced composite had a higher fracture strength average value than endodontically treated teeth. Also, their resistance has been proven to be almost twice as high when compared to that of natural teeth (i.e., teeth not treated endodontically), and also superior to the resistance of premolars reinforced with glass fiber posts. These unexpected results may be due to the fact that, EverX Posterior is a fiberreinforced composite which contains e-glass fibers and barium glass fillers in a tough polymer matrix and is designed to be used under conventional composite as a replacement of dentin in large cavities [30]. To improve its mechanical properties, certain aspects regarding the fibre length, fibre loading and fibre orientation must be taken into consideration. Studies have shown that multidirectional and discontinuous glass fibres from EverX Posterior prevent the material crack propagation (30), while the fibre diameter of $16 \mu \mathrm{m}$ and a wide range of fibre length between 1 and $2 \mathrm{~mm}$ greatly enhance the composite's fracture resistance and change the fracture pattern (33), (34). If the restoration is loaded until failure, the path of fracture is deflected away from the roots. Classically, in order to prevent tooth fracture, the reconstruction technique implied applying the fiber posts in the root canal and pulp chamber and then covering the cusps [32]. Rebilda DC, the flowable dual cured core-buildup material used for cementing the glass fiber posts from group 3, showed high flexural properties, ranging from $6.83 \mathrm{GPa}$ to $8.81 \mathrm{GPa}$, which is most probably related to its monomer system, based on Bis-GMA matrix and additionally on di-UDMA (35). However, it was speculated that other constituents, like Hydroxiethylmethacrylate monomer (HEMA), affect these properties by favouring water sorption and modifying the interatomic forces which are directly responsible for the elastic properties of the material. Having a matrix composition comprising Bis-GMA, UDMA, and triethyleneglycoldimethacrylate (TEGDMA) in its core system and a lower viscosity, Rebilda DC has a high degree of conversion (36). Using a single material for both the core build-up and bonding of the root post was thought to be beneficial to the overall fracture resistance of the tooth, by creating a so called monoblock, which has the same physical properties as the dental hard tissue and responds to stress in the same way and by reducing the bonding between different materials which could affect the stability of the build-up. Surprisingly, and also according to other studies in the literature, the results of the present study showed that the method of reinforcing devitalized endodontically treated teeth with glass fiber posts does not increase their resistance to fracture, on the contrary, it decreases it [37-39]. Several factors may be incriminated, such as: the poor adhesion to radicular dentin, the method of cement application into the root canal and around the fiber post [40], the way of conditioning the surface of the fiber post [41-43] and the need to use more materials and coupling agents between them than in restorative techniques using fiberglass reinforced composite.

Recent studies have shown that a direct coronal reconstruction with composite resin had the ability to increase the fracture resistance of endodontically treated teeth with MOD cavities [32]. Direct reconstruction with composite, together with the adhesive system, has a very high capacity to retrieve occlusal forces and to distribute them to the underlying ligaments and bone through the composite material - dental tissue interface, increasing the tooth's resistance to masticatory loads. However, fiberglass reinforced composite material has the ability to absorb occlusal forces, increases the resistance 
of the tooth to fracture, and decreases the risk of flexion of the cusps, which decreases the risk of marginal infiltration and the appearance of secondary caries [22-26].

There are in vitro studies showing that premolars that are endodontically treated and coronally reconstructed with composite resin without glass fiber posts have a fracture resistance similar to those treated endodontically and reinforced with glass fiber posts [13], thus confirming that any restoration that does not require a special cavity for housing the endodontic post, the sound dental tissues being thereby preserved, increases the fracture resistance of the tooth. Composite materials and glass fiber posts have a different modulus of elasticity than dentine, which causes the fracture lines to propagate into the tooth. The composite material reinforced with fiberglass has the modulus of elasticity equal to that of dentine, absorbing occlusal forces and redistributing them evenly, which in turn protects both the tooth and the filling. Using everX Posterior as a dentine replacement in large cavities and overlaying it with a conventional composite, such as G-aenial Posterior, for enamel replacement creates a biomimetic restoration of the tooth and provides a solution for stronger, more durable posterior composite restoration.

To strengthen the results of the present study, future studies should be performed on a larger number of teeth, both from the frontal, as well from the lateral areas of the oral cavity, aimed at evaluating if the efficacy of composite resin reinforced with fiberglass remains the same, regardless of tooth type and its position on the arch.

\section{Conclusions}

Given the limitations of this study, the fibre-reinforced composite everX Posterior has been shown to increase the fracture resistance of endodontically treated teeth, being more resistant than endodontically treated teeth which were reinforced with fiberglass posts. At the same time, this study showed that EverX Posterior exceeds the fracture resistance of a sound, natural tooth.

\section{References}

1. CARTER, J.M., SORENSEN, S.E., JOHNSON, R.R., et al., Punch shear testing of extracted vital and endodontically treated teeth, J. Biomech., 16(10),1983, 841-848.

2.REEH, E.S., ROSS, G.K., Tooth stiffness with composite veneers: a strain gauge and finite element evaluation, Dent. Mater.,10(4), 1994, 247-252.

3. REEH, E.S., MESSER H.H., DOUGLAS W.H., Reduction în tooth stiffness as a result of endodontic and restorative procedures, J. Endod., 15(11), 1989, 512-515.

4. COHEN, S., BERMAN, L.H., BLANCO, L., BAKLAND, L., KIM J.S., A demographic analysis of vertical root fractures, J. Endod., 32(12), 2006, 1160-1163.

5. DEKON, S., ZAVANELLI, A., RESENDE, C., PAULO, R., NEVES, R., Alternativasclínicas para confecção de núcleosprotéticosestéticos, Rev Bras PrótClín Lab., 4(21), 2002, 387-391.

6. MIREKU, A.S., ROMBERG E., FOUAD A.F., AROLA, D., Vertical fracture of root filled teeth restored with posts: the effects of patient age and dentine thickness, Int Endod J., 43(3), 2010, 218-225.

7. SEOW, L.L., TOH C. G., WILSON NAIM, H.F., Strain measurements and fracture resistance of endodontically treated premolars restored with all-ceramic restorations, J. Dent., 43(1), 2015, 126-132. 8. WILCOX, L.R, ROSKELLEY, C., SUTTON, T., The relationship of root canal enlargement to fingerspreder induced vertical root fracture, J. Endod., 23(8), 1997, 533-534.

9. ROSS, I.F., Fracture susceptibility of endodontically treated teeth, J. Endod., 6, 1980, 560-565.

10. SCHWARTZ, R.S., ROBBINS, J.W., Post placement and restoration of endodontically treated teeth: a literature review, J. Endod., 30, 2004, 289-301.

11. TROPE, M., LANGER, I., MALTZ, D., et al., Resistance to fracture of restored endodontically treated premolars, Endod. Dent. Traumatol., 2, 1986, 35-38.

12. DAHER, R., FEILZER, A. J., KREJCI, I., Novel non-invasive reinforcement of MOD cavities on endodontically treated teeth,J. Dent., 54, 2016, 77-85. 
13.FERNANDES, A.S., SHETTY, S., COUTINHO, I., Factors determining post selection: a literature review, J. Prosthet. Dent., 90, 2003, 556-562.

14.PIERRISNARD, L., BOHIN, F., RENAULT, P., et al., Corono-radicular reconstruction of pulpless teeth: a mechanical study using finite element analysis, J. Prosthet. Dent., 88(4), 2002, 442-448.

15.GONCALVES, L.A., VANSAN, L. P., PAULINO, S. M., Fracture resistance of weakened roots restored with a transilluminating post and adhesive restorative materials, J. Prosthet. Dent., 96(5), 2006, 339-344.

16.STANDLEE, J. P., CAPUTO, A. A., COLLARD, E.W., et al., Analysis of stress distribution by endodontic posts, Oral Surg Oral Med Oral Pathol Oral RadiolEndod., 33(6), 1972, 952-960.

17. FREEDMAN, G.A., Esthetic post-and-core treatment, Dent. Clin. North. Am., 45(1), 2001, 103-116. 18.RADOVIC, I., MAZZITELLI, C., CHIEFFI, N., et al., Evaluation of the adhesion of fiber posts cemented using different adhesive approaches, Eur. J. Oral Sci., 116(6), 2008, 557-563.

19.GEHRCKE, V., OLIVIERA, M., AARESTRUP, F., et al., Fracture Strength of Flared Root Canals Restored with Different Post Systems, Euro Endod. J., 24, 2017, 2-6.

20.TORABI, K., FATTAHI, F., Fracture resistance of endodontically treated teeth restored by different FRC posts: an în vitro study, Indian J. Dent. Res., 20(3), 2009, 282-287.

21.MAGNE, P., KNEZEVIC, A., Influence of overlay restorative materials and load cusps on the fatigue resistance of endodontically treated molars, Quintessence Int., 40, 2009, 729-737.

22.NEWMAN, M.P., YAMAN, P., DENNISON, J., Fracture resistance of endodontically treated teeth restored with composite posts, J. Prosthet. Dent., 89(4), 2003, 360-367.

23.COBANKARA, F. K., UNLU, N., CETIN, A.R., et al., The effect of different restoration techniques on the fracture resistance of endodontically-treated molars, Oper. Dent., 33(5), 2008, 526-353.

24.GAROUSHI, S., TANNER, J., VALLITTU, P.K., LASSILA L.V.J., Preliminary clinical evaluation of short fiber-reinforced composite resin în posterior teeth: 12-months report, Open. Dent. J., 6, 2012, 41-45.

25.GAROUSHI S., SAILYNOJA, E., VALLITTU, P.K., LASSILA, L., Physical properties and depth of cure of a new short fiber reinforced composite, Dent. Mater., 29, 2013, 835-841.

26. GAROUSHI S., HATEM, M., LASSILA, L., VALLITTU, P. K., The effect of short fiber composite base on microleakage and load bearing capacity of posterior restorations, Acta. Biomater. Odontol. Scand, 1, 2015, 6-12.

27.GAROUSHI, S., VALLITTU, P. K., LASSILA, L. V. J., Short glass fiber reinforced restorative composite resin with semi-interpenetrating polymer network matrix, Dent. Mater., 23, 2007, 1356-1362. 28.FRATER, M., FORSTER, A., KERESZTURI, M., et al., in vitro fracture resistance of molar teeth restored with a short fibre-reinforced composite material, J. Dent., 42(9), 2014, 1143-1145.

29.GRADINARU, I., IGNAT, L., GENA DASCALU, C., SOROAGA, L.V., ANTOHE, M.E., Studies Regarding the Architectural Design of Various Composites and Nanofibres Used in Dental Medicine, Rev.Chim., 69(2), 2018, 328-331.

30.TEKCE N, AYDEMIR S, DEMIRCI M, TUNCER S, SANCAK Eİ, BAYDEMIR C. Clinical Performance of Direct Posterior Composite Restorations with and without Short Glass-fiber-reinforced Composite in Endodontically Treated Teeth: 3-year Results. J Adhes Dent. 2020;22(2):127-137

31.BITTER K, GLASER C, NEUMANN K, BLUNCK U, FRANKENBERGER R. Analysis of resindentin interface morphology and bond strength evaluation of core materials for one stage postendodontic restorations. PLoS One. 2014 Feb 28;9

32.NICOLA, S., ALBERTO, F., RICCARDO, M.T., et al., Effects of fiber-glass-reinforced composite restorations on fracture resistance and failure mode of endodontically treated molars, J. Dent., 53, 2016, 82-87.

33.ABOUELLEIL H, PRADELlE N, VILlAT C, ATTIK N, COLON P, GROSGOGEAT B. Comparison of mechanical properties of a new fiber reinforced composite and bulk filling composites. Restor Dent Endod. 2015 Nov;40(4):262-70. 
34.GAROUSHI S, VALLITTU PK, LASSILA L. Mechanical Properties and Wear of Five Commercial Fibre-Reinforced Filling Materials. Chin J Dent Res. 2017;20(3):137-143.

35.FLOYD CJ, DICKENS SH. Network structure of Bis-GMA- and UDMA-based resin systems. Dent Mater. 2006 Dec;22(12):1143-9.

36.AKSORNMUANG J, NAKAJIMA M, FOXTON RM, TAGAMI J. Mechanical properties and bond strength of dual-cure resin composites to root canal dentin. Dent Mater. 2007 Feb;23(2):226-34.

37.PEREIRA, J.R., DO VALLE, A.L., et al., The effect of post material on the characteristic strength of fatigued endodontically treated teeth, J. Prosthet. Dent., 112(5), 2014, 1225-1230.

38. PANG, J., FENG, C., Fracture behaviors of maxillary central incisors with flared root canals restored with CAD/CAM integrated glass fiber post-and-core, Dent. Mater. J., 38(1), 2019, 114-119.

39.GUTMAN, J.L., DUMSHA, T.C., LOVDAHL, P.E., Problem solving în endodontics, $4^{\text {th }}$ Edition, Elsevier Mosby, St. Louis, 2006, 86-89, 538-543, 551.

40.CALIXTO LR, BANDECA MC, CLAVIJO V, AANDRADE MF, VAZ LG, CAMPOSEA. Effect of resin cement system and root region on the push-out bond strength of a translucent fiber post. Oper Dent. 2012 Jan-Feb;37(1):80-6.

41.BALBOSH A, KERN M. Effect of surface treatment on retention of glass-fiber endodontic posts. J Prosthet Dent. 2006 Mar;95(3):218-23.

42.SKUPIENJA, SARKIS-ONOFRE R, CENCI MS, MORAES RR, PEREIRA-CENCI T. A systematic review of factors associated with the retention of glass fiber posts. Braz Oral Res. 2015;29.

43.MURARIU A, DINU C, AGOP FORNA D, STEFANESCU2 V, TOPOR G, FORNA NC, FOTEA S, GURAU G, IORDACHE C. Composite Resins - Multifunctional Restorative Material and Practical Approaches in Dental Field. Mater. Plast., 57(2), 2020, 276-284

Manuscript received: 10.11 .2020 